\title{
Osteossíntese de úmero em pombos domésticos (Columba livia) associando-se pinos metálicos e polimetilmetacrilato intramedulares após osteotomia diafisária
}

\author{
[Humerus osteosynthesis using intramedullary pins and polymethylmethacrylate in \\ domestic pigeons (Columba livia)] \\ M.M. Alievi ${ }^{1}$, A.N.C. Oliveira ${ }^{2}$, P.A. Ferreira ${ }^{2}$, C. Traesel $^{2}$, L.D. Guimarães ${ }^{3}$, \\ F. Flores ${ }^{4}$, S.F. Silva ${ }^{2}$, J.E.W. Schossler ${ }^{2}$ \\ ${ }^{1}$ Faculdade de Veterinária - UFRGS \\ Av. Bento Gonçalves, 9090 \\ 91540-000 - Porto Alegre, RS \\ ${ }^{2}$ Universidade Federal de Santa Maria - Santa Maria, RS \\ ${ }^{3}$ Universidade Federal do Mato Grosso - Cuiabá, MT \\ ${ }^{4}$ Universidade Estadual de Santa Catarina - Lages, SC
}

\begin{abstract}
RESUMO
Foram utilizadas 28 aves adultas, separadas aleatoriamente em quatro grupos. Os pombos foram anestesiados com isoflurano para a realização da osteotomia diafisária transversa do úmero direito. No grupo I, a osteossíntese foi realizada associando-se dois pinos de Kirschner e polimetilmetacrilato, intramedulares; no grupo II, os pinos de Kirschner foram substituídos por pinos de Schanz; no grupo III, foram utilizados apenas dois pinos de Kirschner; e, no grupo IV, apenas dois pinos de Shanz. Os tempos médios para a consolidação óssea foram de $29 \pm 4,04$ dias no grupo I; $24 \pm 5,29$ dias no grupo II; 33 $\pm 3,74$ dias no grupo III; e 32,9 9 5,21 dias no grupo IV. Foi observada migração dos pinos em 42,9\% dos animais do grupo I, em $0 \%$ nos do grupo II, em $85,7 \%$ nos do grupo III, e em $28,6 \%$ nos do grupo IV. Em duas aves dos grupos I, III e IV notou-se incapacidade de voar. Os resultados demonstram que a associação de dois pinos de Schanz e polimetilmetacrilato, ambos intramedulares, é um método efetivo para osteossíntese de úmero em pombos domésticos (Columba livia), proporcionando rápida consolidação óssea e mínimas complicações.
\end{abstract}

Palavras-chave: aves, fratura, osteossíntese, úmero

\begin{abstract}
Twenty-eight adult domestic pigeons (Columba livia) were randomly divided into four groups of seven birds each. Anesthesia was performed with isoflurane and oxygen, and an osteotomy of the right humerus midshaft was performed with an electric cutter. On the sequence, one of the following treatments was chosen: group I, two Kirschner pins and polymethylmethacrylate intramedullary; group II, two Schanz pins and polymethylmethacrylate intramedullary; group III, two Kirschner pins only; and group IV, two Schanz pins only. The mean time \pm standard deviation for fracture healing was $29 \pm 4.04$ days in group I; $24 \pm 5.29$ days in group II; $33 \pm 3.74$ days in group III; $32.9 \pm 5.21$ days in group IV. Pin migration was observed in $42.9 \%$ of the group I animals, $0 \%$ of group II, $85.7 \%$ of group III, and $28.6 \%$ of group IV. Two pigeons of groups I, III, and IV presented flight incapability. The results suggest that two Schanz pins and polymethylmethacrylate intramedullary are an effective method of humeral ostheosynthesis in domestic pigeons (Columba livia), resulting in faster fracture healing with minimal complications.
\end{abstract}

Keywords: birds, fracture, orthopaedic, humerus

Recebido em 29 de agosto de 2007

Aceito em 3 de junho de 2008

E-mail: marcelo.alievi@ufrgs.br 


\section{INTRODUÇÃO}

Os ossos das aves possuem baixo peso, formato aerodinâmico, sendo finos e com corticais quebradiças (Levitt, 1989). O úmero e o fêmur são ossos pneumáticos, diminuindo assim o peso corporal, facilitando o vôo e a umidificação do ar (Bennett e Kuzma, 1992).

O tratamento de fraturas em aves com o uso apenas de pinos intramedulares é bastante difícil, pois como os ossos possuem cavidade medular muito larga, normalmente os pinos não conseguem preenchê-la adequadamente e, desse modo, não ficam adequadamente ancorados, resultando em dificuldade para evitar as forças de rotação (Levitt, 1989). Para inibir tais forças, um método auxiliar de fixação deve ser utilizado (Newton e Zeitlin, 1977; Levitt, 1989). A associação de pinos intramedulares com cerclagens de fio de aço permite adequada imobilização do foco da fratura (Alievi et al., 1998). Bandagens também são utilizadas com resultados satisfatórios (Kuzma, 1995).

Resultados funcionais insatisfatórios podem ser causados pela migração dos pinos intramedulares para a superfície articular, provocando a destruição da cartilagem articular e lesões aos tecidos moles como músculos e tendões (Newton e Zeitlin, 1977). Ocasionalmente pinos intramedulares podem causar lesões na epífise e no endósteo dos ossos, afetando o suprimento sangüíneo, resultando em necrose óssea (Yamazoe et al., 1994).

O polimetilmetacrilato (PMMA) não possui propriedade adesiva (Borman et al., 1978; Putney et al., 1983; Kuzma, 1995), porém, injetado no canal medular, atua como uma "cola" mecânica quando em superfícies irregulares, fixando-se a elas (Putney et al., 1983; Kuzma, 1995). Ele deve ser injetado na forma líquida no interior do canal medular, levando cerca de 10 minutos para solidificar, atingindo cerca de $100^{\circ} \mathrm{C}$ durante esse processo (Kuzma, 1995).

Putney et al. (1983) e Yamazoe et al. (1994), ao utilizarem PMMA intramedular como método de osteossíntese de úmero em aves, verificaram que o mesmo não é tóxico, porém algum grau de necrose ocorre devido à liberação de calor durante a polimerização. Após cerca de dez dias as células necróticas são eliminadas e a consolidação da fratura progride adequadamente (Putney et al., 1983). Normalmente o PMMA é encapsulado por uma fina camada de tecido fibroso (Mathews et al., 1994; Yamazoe et al., 1994) e, após quatro semanas, algumas células gigantes podem ocorrer na interface tecido fibroso/polimetilmetacrilato. Entretanto, passadas 12 semanas da cirurgia, essas células não são mais observadas (Yamazoe et al., 1994).

Quando somente PMMA é utilizado no canal medular para o tratamento de fraturas em aves, normalmente ocorrem movimentação e afastamento dos fragmentos ósseos (Yamazoe et al., 1994), devendo-se associar um método de imobilização externa (Borman e Putney, 1978; Borman et al., 1978). Yamazoe et al. (1994) observaram que a fixação externa, com o uso de bandagens, causa grande estresse em pombos, eventualmente levando a refratura devido a sucessivas quedas por dificuldade de equilíbrio.

Kuzma e Hunter $(1989 ; 1991)$ e Yamazoe et al. (1994) associaram placa e parafusos metálicos com PMMA intramedular para a realização de osteossíntese em aves, observando que o PMMA serviu de substrato para a fixação dos parafusos, proporcionando estabilidade à fratura sem a ocorrência de afrouxamento dos implantes metálicos ou falha na imobilização. O PMMA possui baixo peso e não afetou a habilidade de vôo das aves (Kuzma e Hunter, 1991); após seis semanas, as aves retornaram ao vôo normalmente (Yamazoe et al., 1994).

O objetivo do presente estudo foi avaliar comparativamente o uso de pinos metálicos, lisos (Kirschner) ou com rosca negativa na extremidade (Schanz), associados ou não ao polimetilmetacrilato, ambos intramedulares, no tratamento de fraturas diafisárias transversas de úmero em pombos domésticos (Columba livia).

\section{MATERIAL E MÉTODOS}

Foram utilizados 28 pombos domésticos adultos, com pesos entre 350 e $450 \mathrm{~g}$. As aves, alojadas individualmente em gaiolas $(80 \times 50 \times 50 \mathrm{~cm})$, receberam água e ração à vontade. Após um período de adaptação de, no mínimo, 15 dias, foram aleatoriamente separadas em quatro grupos de sete animais. No grupo I, foi realizada osteossíntese de úmero associando-se pinos de 
Kirschner e polimetilmetacrilato; no grupo II, foram utilizados pinos de Schanz e polimetilmetacrilato; no grupo III, somente pinos de Kirschner e no grupo IV, somente pinos de Schanz.

Após jejum sólido de aproximadamente seis horas, cada ave recebeu como medicação préanestésica $3 \mathrm{mg} \cdot \mathrm{kg}^{-1}$ de tartarato de butorfanol ${ }^{1}$ pela via intramuscular (músculo peitoral). Após 15 minutos, a anestesia geral foi induzida com isoflurano ${ }^{2}$ e oxigênio, utilizando máscara facial, e mantida com os mesmos gases por meio de tubo orotraqueal.

Com o animal em plano cirúrgico de anestesia, foi efetuada a remoção manual das penas localizadas na região dorsal do úmero direito e com a ave em decúbito lateral esquerdo, a antissepsia da área foi realizada com gluconato de clorexidina $4 \%$. Como profilaxia antimicrobiana, foram administrados $100 \mathrm{mg} \cdot \mathrm{kg}^{-1}$ de ampicilina sódica ${ }^{3}$ pela via intramuscular cerca de 30 minutos antes da cirurgia.

Após a colocação dos panos de campo, uma incisão de pele de aproximadamente $2 \mathrm{~cm}$ foi efetuada na face dorsal da região umeral. Para a exposição da região diafisária do úmero, o músculo bíceps braquial foi retraído cranialmente, a cabeça escapular do tríceps braquial e o deltóide maior foram rebatidos caudalmente, protegendo o nervo radial. Com um motor elétrico e uma broca odontológica de $0,2 \mathrm{~mm}$ foi efetuada a osteotomia diafisária transversa. Durante esse procedimento a área foi continuamente irrigada com solução fisiológica estéril.

Após a osteotomia, nas aves do grupo I, dois pinos de Kirschner, com $1,25 \mathrm{~mm}$ de diâmetro, foram introduzidos de forma retrógrada no fragmento proximal da fratura, emergindo através da crista deltóide. Imediatamente após esse procedimento, foi preparado, em frasco estéril, pequena quantidade de $\mathrm{PMMA}^{4}$. Para tal, $1 \mathrm{~g}$ do polímero sólido e $0,5 \mathrm{ml}$ do monômero líquido foram misturados por cerca de um minuto. O PMMA, ainda na forma pastosa, foi

\footnotetext{
${ }^{1}$ Torbugesic, Fort Dodge - Campinas, Brasil.

${ }^{2}$ Isoforine, Cristália - Itapira, Brasil.

${ }^{3}$ Ampicilina, Biochimico - Rio de Janeiro, Brasil.

${ }^{4}$ Cimento Ortopédico Radiopaco, Biomecânica Ltda - Jaú, Brasil.
}

colocado no interior de uma seringa de $3 \mathrm{ml}$ e, por meio de uma agulha $40 \times 12 \mathrm{~mm}$, injetado no canal medular do fragmento distal da fratura. A fratura foi reduzida e os pinos de Kirschner introduzidos no canal medular do fragmento distal. As extremidades dos pinos foram cortadas o mais próximo possível à crista deltóide. A área cirúrgica foi irrigada com solução fisiológica por cerca de 10 minutos, tempo necessário para polimerização do PMMA e, após esse período, os músculos foram aproximados com sutura contínua simples e fio absorvível sintético ${ }^{5}$ e a pele com sutura isolada simples e mesmo fio.

Nos pombos do grupo II, foram realizados os mesmos procedimentos do grupo I, porém ao invés de serem utilizados pinos de Kirschner foram utilizados pinos de Schanz com a rosca introduzida na extremidade distal da fratura. Nos do grupo III, a osteossíntese foi realizada apenas com os pinos de Kirschner, sem PMMA, e nos do grupo IV, somente pinos de Schanz.

Como terapia analgésica e antiinflamatória as aves receberam $5 \mathrm{mg} \cdot \mathrm{kg}^{-1}$ de flunixin meglumine ${ }^{6}$, pela via intramuscular, logo após a recuperação anestésica e essa medicação foi repetida por mais duas vezes, com intervalo de 24 horas entre cada administração. Em todos os animais a asa operada foi imobilizada junto ao corpo com bandagem por um período de 15 dias.

Logo após o término da cirurgia, as aves foram encaminhadas ao setor de radiologia, para avaliação radiográfica do úmero. Após 15 dias, as radiografias foram realizadas semanalmente até o completo desaparecimento da linha de fratura, período considerado como tempo necessário para a consolidação óssea. Passados 90 dias do procedimento cirúrgico, todas as aves foram submetidas à nova avaliação radiográfica. Todas avaliações foram realizadas em incidências ventro-dorsal e caudo-cranial.

Diariamente foi realizada inspeção das aves, observando-se estado geral, apetite, atividade, aspecto das fezes e facilidade de manter-se em estação. Os animais que apresentaram alterações clínicas importantes, tais como, sinais de estresse, dificuldade em adaptar-se à bandagem,

${ }^{5}$ Polycryl, Polysuture Ind. e Com. Ltda - São Sebastião do Paraíso, Brasil.

${ }^{6}$ Banamine, Schering Plough Ltda - Rio de Janeiro, Brasil. 
não se alimentou ou permaneceu hipoativo, foram imediatamente sacrificados e substituídos.

Até a consolidação radiográfica da fratura as aves foram mantidas em gaiolas individuais, e, após, foram transferidas para um viveiro coletivo $(6 \times 2 \times 2,5 \mathrm{~m})$, onde permaneceram até o 90 o dia de pós-operatório para avaliação do uso funcional da asa e de possíveis complicações tardias, como por exemplo, refratura, osteomielite ou migração dos pinos.

Para a análise estatística foi utilizado o pacote estatístico Statistical Package for Social Sciences, versão 8.0, e nível de significância de 0,05 . O tempo de consolidação das fraturas nos diferentes grupos foi submetido ao teste KruskalWallis e ao teste Mann-Whitney.

\section{RESULTADOS E DISCUSSÃO}

Os dados referentes às médias e aos desviospadrão do tempo de consolidação das fraturas nos diferentes grupos são apresentados na Tab. 1 e a porcentagem das complicações, na Fig. 1.

Apesar de existirem outros métodos de osteotomia em aves como, por exemplo, serra oscilatória (Wander et al., 2000), osteótomo (Putney et al., 1983) e pressão digital (Williams et al., 1987; Alievi et al., 2002), neste trabalho foi utilizada broca cilíndrica odontológica (diâmetro 0,2mm) acoplada a um motor elétrico. Tal técnica foi de fácil utilização e, principalmente, produziu em todas as aves osteotomias similares, o que é fundamental quando se comparam métodos de osteossíntese.

Tabela 1. Média e desvio-padrão do tempo de consolidação das fraturas diafisárias de úmero em pombos domésticos (Columba livia) nos diferentes grupos de tratamento.

\begin{tabular}{lcc}
\multicolumn{1}{c}{ Tratamento } & \multicolumn{2}{c}{ Dias para consolidação } \\
\cline { 2 - 3 } & \multicolumn{1}{c}{ Média } & Desvio-padrão \\
\hline Grupo I (pinos lisos e polimetilmetacrilato) & $29 \mathrm{a}, \mathrm{b}$ & 4,04 \\
Grupo II (pinos com rosca e polimetilmetacrilato) & $24 \mathrm{a}$ & 5,29 \\
Grupo III (pinos lisos) & $33 \mathrm{~b}$ & 3,74 \\
Grupo IV (pinos com rosca) & $32,9 \mathrm{~b}$ & 5,21 \\
\hline
\end{tabular}

Médias seguidas por letras distintas diferem entre si pelo teste Mann-Whitney $(\mathrm{P}<0,05)$.

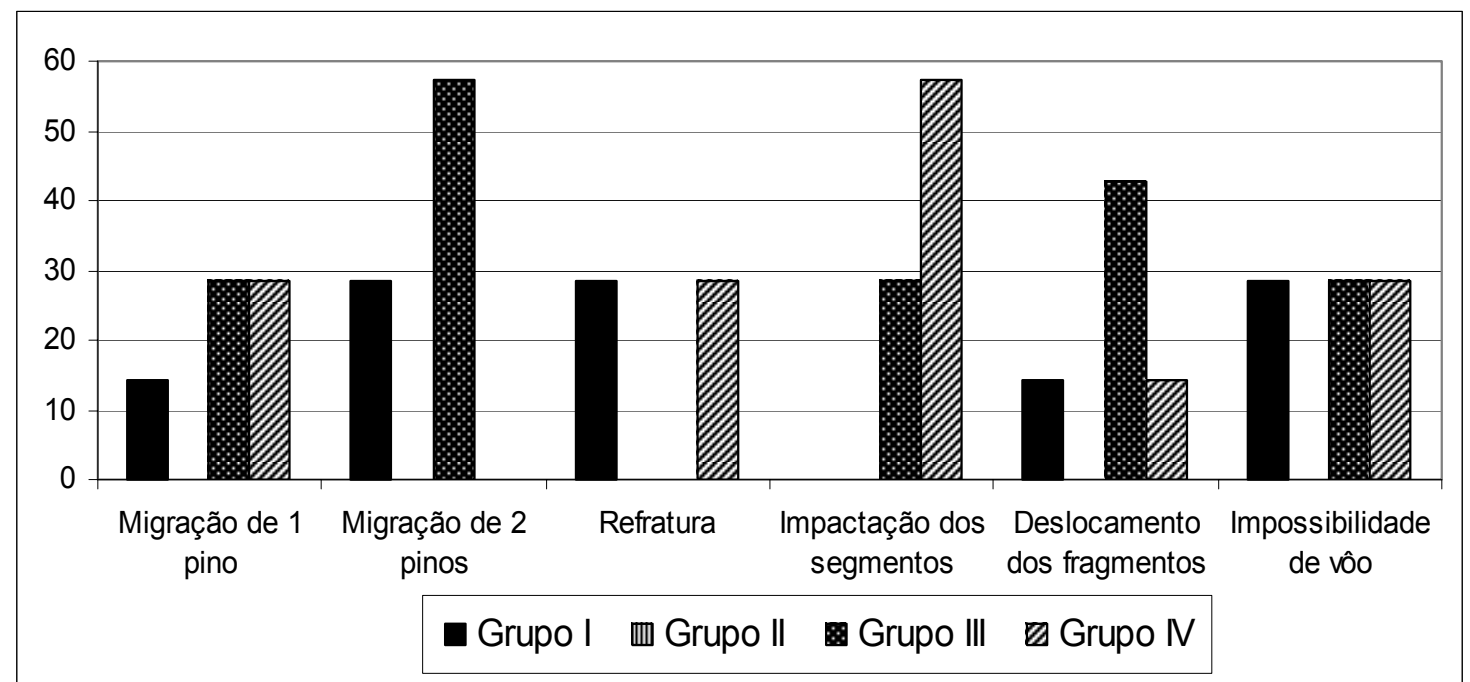

Figura 1. Porcentagem das complicações ocorridas nos diferentes grupos de tratamento das fraturas diafisárias de úmero em pombos domésticos (Columba livia).

Grupo I: pinos de Kirschner e polimetilmetacrilato; grupo II: pinos de Schanz e polimetilmetacrilato (ausência de complicações); grupo III: somente pinos de Kirschner; grupo IV: somente pinos de Schanz. 

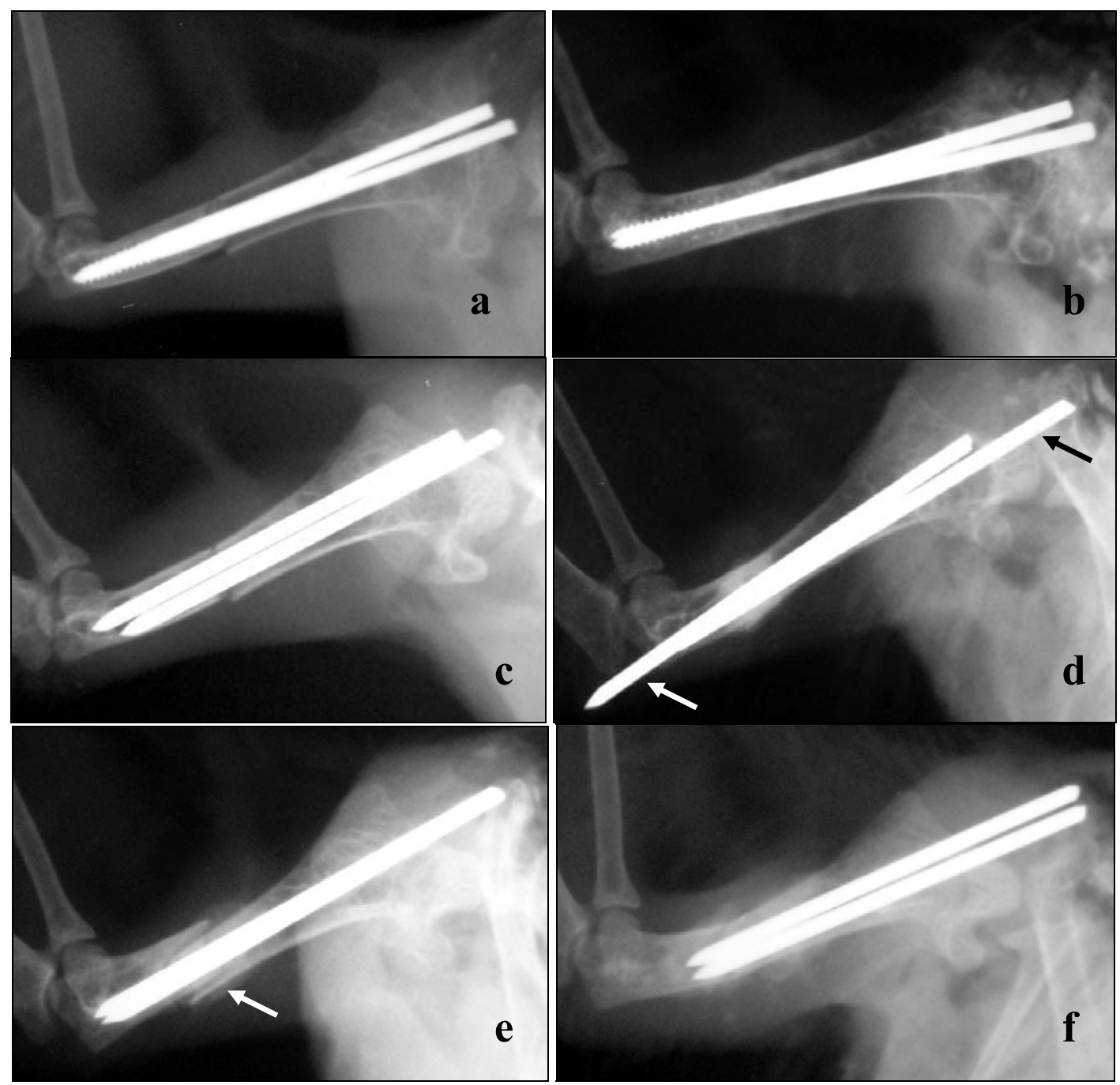

Figura 2. a) Pós-operatório imediato de ave do grupo II. Notar o correto alinhamento dos fragmentos ósseos e o posicionamento adequado dos pinos. b) Pós-operatório (29 dias) de ave do grupo II. Observar a consolidação óssea adequada e a manutenção da posição dos pinos. c) Pós-operatório imediato de ave do grupo III. Notar o correto alinhamento dos fragmentos ósseos e o posicionamento adequado dos pinos. d) Pós-operatório tardio (15 dias) de ave do grupo III. Notar a migração dos pinos (setas) e a impactação dos fragmentos ósseos. e) Pós-operatório (15 dias) de ave do grupo III. Notar a impactação dos fragmentos (seta). f) Pós-operatório (15 dias) de ave do grupo III. Notar a migração dos pinos.

Grupo II: pinos de Schanz associados ao polimetilmetacrilato; grupo III: somente pinos de Kirschner.

Apesar da imobilização externa ter sido efetuada apenas na asa submetida à cirurgia, o que, segundo Spink (1978) e Bennett e Kuzma (1992), facilitaria a adaptação precoce do animal a esse método de imobilização, quatro aves foram submetidas à eutanásia e substituídas por não se adaptarem a imobilização externa, apresentando dificuldade em equilibrar-se e, assim, incapacidade de permanecer em estação. Tal fato também foi relatado por Yamazoe et al. (1994). Esses autores citaram a ocorrência de grande estresse nas aves e refratura devido a sucessivas quedas.
Embora a ampicilina sódica seja um antimicrobiano de espectro limitado, e não seja o mais indicado para a profilaxia em cirurgia ortopédica (Raiser, 2000), ela foi adequada, pois nenhuma ave apresentou sinais de infecção no pós-operatório, mesmo que não tenham sido realizados quaisquer cuidados tópicos na ferida cirúrgica, em virtude da impossibilidade de acesso a esta, devido à imobilização da asa com a bandagem por 15 dias. Outra opção para profilaxia cirúrgica seria a incorporação de antimicrobianos ao PMMA, o qual, em estudos 
in vitro, inibiria o crescimento bacteriano por sete a 10 dias. Porém, tal adição poderia afetar a resistência compressiva do PMMA (Weisman et al., 2000).

Apesar de o PMMA não possuir propriedades adesivas (Borman et al., 1978; Putney et al., 1983; Kuzma, 1995), não foi verificado nenhum caso de migração. Esse fato deve-se à capacidade do PMMA, quando utilizado na forma pastosa, penetrar nas reentrâncias e saliências ósseas e, assim, ficar adequadamente ancorado (Putney et al., 1983; Kuzma, 1995).

A utilização de PMMA apenas no fragmento distal da fratura deveu-se à necessidade da criação de uma área para fixação adequada dos pinos nesse fragmento, pois como o úmero é um osso pneumático e apresenta cortical muito fina (Levitt, 1989), haveria dificuldade para a fixação adequada dos pinos no fragmento distal. Esse fato foi comprovado neste trabalho pela alta freqüência de migração dos pinos nos grupos em que não foi utilizado PMMA. A não utilização de o PMMA no fragmento proximal deveu-se à transfixação da crista deltóide do úmero pelos pinos, proporcionando assim uma área de ancoragem.

Putney et al. (1983) e Yamazoe et al. (1994) relataram que a polimerização do PMMA acarretou necrose térmica, o que poderia retardar o tempo para consolidação da fratura. No presente trabalho não foi verificado tal problema, observando-se justamente o contrário, isto é, nos grupos em que o PMMA foi utilizado, a consolidação ocorreu mais precocemente. Isso demonstra que a imobilização do sítio de fratura proporcionada pela associação dos pinos ao PMMA foi mais importante que a necrose térmica provocada pela polimerização. Uma manobra que, provavelmente, contribuiu para diminuição da lesão térmica provocada pela polimerização foi a contínua aplicação de solução fisiológica no sítio de cirurgia, o que acarretou uma rápida dissipação do calor e, dessa forma, menos lesões térmicas.

A freqüência de migração dos pinos no grupo onde foi associado PMMA e pinos de Kirschner foi considerada alta, principalmente quando se compara com os grupos que não utilizaram PMMA. Porém, esse fato pode ser explicado pela propriedade não adesiva do PMMA e pela superfície lisa dos pinos, o que não fornece área adequada para a fixação deste. Cabe ressaltar que todos os casos de migração dos pinos ocorridos neste trabalho aconteceram até o 15 o dia de pósoperatório, não sendo observados novos casos até o 90o dia, mesmo quando vôos eram realizados regularmente. Esse fato é muito importante quando se trabalha com aves que serão reintroduzidas na natureza, pois elas não poderão ser continuamente avaliadas. Assim, as técnicas utilizadas não devem apresentar complicações em longo prazo.

Wander et al. (2000) utilizaram três pinos intramedulares de Kirschner $(1,25 \mathrm{~mm})$ para a osteossíntese de úmero em pombos domésticos, e diferentemente do ocorrido no presente trabalho não verificaram migração e justificaram que a fricção entre os pinos preveniu a migração. Os animais utilizados por esses autores não foram submetidos a testes de vôo, o que seria importante, pois a inserção de três pinos intramedulares poderia afetar a capacidade de vôo das aves, devido ao excesso de peso. Além disso, o preenchimento maciço do canal medular poderia resultar em danos ao suprimento ósseo endosteal, provocando retardo na consolidação (Yamazoe et al., 1994). A utilização do PMMA intramedular, além de promover adequada fixação dos pinos com rosca (Schanz), acelerando a consolidação óssea e evitando complicações como a migração dos pinos e a impactação dos segmentos ósseos, evitou a necessidade de se aumentar o número de pinos intramedulares.

A migração dos pinos nos grupos onde não foi utilizado PMMA justifica-se também pelas características anatômicas do úmero, um osso pneumático, com cortical muito fina e ampla cavidade medular, com trabéculas esparsas que dificultaram a fixação dos pinos (Levitt, 1989).

A alta freqüência de impactação dos fragmentos nos grupos em que não foi utilizado PMMA pode ser explicada pela capacidade deste em servir como anteparo para o fragmento ósseo proximal, além de proporcionar maior estabilidade para os fragmentos ósseos.

Yamazoe et al. (1994) e Kuzma e Hunter (1989; 1991) associaram o PMMA a placas metálicas, indicando que tal método foi eficiente para a osteossíntese em aves. Apesar dos resultados 
satisfatórios, o uso de placas e parafusos requer maior treinamento da equipe cirúrgica, material especializado e apresenta maior custo que a utilização de pinos metálicos intramedulares.

Apesar dos pinos intramedulares não terem sido removidos após a consolidação das fraturas, acredita-se que tal manobra seria possível, pois como eles não foram completamente inseridos no canal medular do úmero, uma pequena extremidade deles era facilmente palpada junto a crista deltóide, o que permitiria a sua apreensão e remoção. Mesmo no grupo II, em que foram associados pinos com rosca e PMMA isso provavelmente seria possível, porém, ao invés de simples tração dos pinos, eles mesmos deveriam ser girados no sentido anti-horário.

\section{CONCLUSÕES}

Pode-se concluir que a associação entre pinos com rosca negativa (Schanz) e polimetilmetacrilato intramedulares promove redução significativa no tempo de consolidação de fraturas de úmero em pombos domésticos, quando comparada à osteossíntese com o uso, apenas, de pinos de Kirschner ou de Schanz. A associação de pinos de Schanz e polimetilmetacrilato não apresenta complicações. Já a associação de pinos de Kirschner e polimetilmetacrilato, ou o uso isolado de pinos de Schanz ou de Kirschner apresenta complicações como refratura, impactação e deslocamento dos fragmentos, levando freqüentemente à incapacidade de vôo.

\section{AGRADECIMENTO}

Os autores agradecem a empresa Biomecânica Indústria e Comércio de Produtos Ortopédicos Ltda. pela doação do cimento ortopédico radiopaco.

\section{REFERÊNCIAS BIBLIOGRÁFICAS}

ALIEVI, M.M.; SCHOSSLER, J.E.; TEIXEIRA, M. Osteossíntese de úmero em arara-canindé (Ara ararauna): relato de caso. Clin. Vet., n.15, p.18-20, 1998.

ALIEVI, M.M.; SCHOSSLER, J.E.; HIPPLER, R.A. et al. Redução fechada e fixação esquelética externa tipo I para tratamento de fraturas de tibiotarso em pombos domésticos (Columba livia). Arq. Bras. Med. Vet. Zootec., v.54, p.259266, 2002.

BENNETT, R.A.; KUZMA, A.B. Fracture management in birds. J. Zoo. Wildl. Med., v.23, p.5-38, 1992.

BORMAN, E.R.; PUTNEY, D.L. Repair of a wing fracture with methyl methacrylate bone cement. Vet. Med., v.73, p.794, 1978.

BORMAN, E.R.; PUTNEY, D.L.; JESSUP, D. Use of acrylic bone cement in avian orthopedics. J. Am. Anim. Hosp. Assoc., v.14, p.602-604, 1978.

KUZMA, A.B.; HUNTER, B. Osteotomy and derotation of the humerus in a turkey vulture using intramedullary polymethylmethacrylate and bone plate fixation. Can. Vet. J., v.30, p.900901, 1989.

KUZMA, A.B.; HUNTER, B.A new technique for avian fracture repair using intramedullary polymethylmethacrylate and bone plate fixation. J. Am. Anim. Hosp. Assoc., v.27, p.239-248, 1991.

KUZMA, A. Avian orthopedics: fracture management. In: ACVS VETERINARY SYMPOSIUM, 1995, Chicago. Proceedings... Chicago: American College of Veterinary Surgeons, 1995. p.249-254.

LEVITT, L. Avian orthopedics. Comp. Cont. Educ. Pract. Vet., v.11, p.899-929, 1989.

MATHEWS, K.G.; WALLACE, L.J.; REDIG, P.T. et al. Avian fracture healing following stabilization with intramedullary polyglycolic acid rods and cyanoacrylate adhesive vs. polypropylene rods and polymethylmethacrylate. Vet. Comp. Orthop. Traumatol., v.7, p.158-169, 1994.

NEWTON, C.D.; ZEITLIN, S. Avian fracture healing. J. Am. Vet. Med. Assoc., v.170, p.620$625,1977$.

PUTNEY, D.L.; BORMAN, E.R.; LOHSE, C.L. Methylmethacrylate fixation of avian humeral fractures: a radiographic histologic study. J. Am. Anim. Hosp. Assoc., v.19, p.773-782, 1983.

RAISER, A.G. Homoimplante ortotópico de tendão calcâneo comum, conservado em glicerina a 98\%, e tratado com radiação laser arseneto de gálio, sob dois métodos de imobilização, em cães. 2000. 88f. Tese 
(Doutorado) - Universidade Federal de Santa Maria, Santa Maria, RS.

SPINK, R.R. Fracture repair in rehabilitation of raptors. Vet. Med., v.73, p.1451-1455, 1978.

WANDER, K.W.; SCHWARZ, P.D.; JAMES, S.P. et al. Fracture healing after stabilization with intramedullary xenograft cortical bone pins: a study in pigeons. Vet. Surg., v.29, p.237-244, 2000 .

WEISMAN, D.L.; OLMSTEAD, M.L.; KOWALSKI, J.J. In vitro evaluation of antibiotic elution from polymethylmethacrylate
(PMMA) and mechanical assessment of antibiotic-PMMA composites. Vet. Surg., v.29, p.245-251, 2000.

WILLIAMS, R.; HOLLAND, M.; MILTON, J.L. et al. A comparative study of treatment methods for long bone fractures. Comp. Anim. Pract., v.1, p.48-55, 1987.

YAMAZOE, K.; HIBINO, C.; KUDO, T. et al. The reduction of humeral fracture in pigeons with intramedullary poly (methylmethacrylate) and neutralization plate fixation. J. Vet. Med. Sci., v.56, p.739-745, 1994. 